\title{
In vivo neutralization of Cryptobia salmositica metallo-protease by $\alpha 2$-macroglobulin in the blood of rainbow trout Oncorhynchus mykiss and in brook charr Salvelinus fontinalis
}

\author{
X. Zuo, P. T. K. Woo* \\ Department of Zoology, University of Guelph, Guelph, Ontario, Canada N1G 2W1
}

\begin{abstract}
Cryptobia salmositica infects both rainbow trout Oncorhynchus mykiss and brook charr Salvelinus fontinalis, but it does not cause disease (e.g. anaemia) in brook charr. The natural antiprotease, $\alpha 2$-macroglobulin $(\alpha 2-\mathrm{M})$, was found in the blood of rainbow trout and brook charr, but it had much higher activity in brook charr. Under in vivo conditions, $\alpha 2-\mathrm{M}$ of trout and charr were neutralized by $C$. salmositica extracellular protease. The onset and persistence of anaemia in infected rainbow trout were related to low levels of $\alpha 2-\mathrm{M}$. Infected brook charr did not develop anaemia as $\alpha 2-\mathrm{M}$ remained high during the infection. Secreted metallo-protease of $C$. salmositica was detected in the blood of infected rainbow trout when its $\alpha 2-\mathrm{M}$ was low and the fish was anaemic; however, metallo-protease was not detected in infected brook charr. We suggest that host $\alpha 2-\mathrm{M}$ plays an important role in defense against cryptobiosis by inhibiting the activity of metallo-protease secreted by the pathogenic C. salmositica.
\end{abstract}

KEY WORDS: $\alpha 2$-macroglobulin - Oncorhynchus mykiss $\cdot$ Salvelinus fontinalis $\cdot$ Cryptobia salmositica Protease

\section{INTRODUCTION}

Cryptobia salmositica Katz, 1951 (Sarcomastigophora: Kinetoplastida) is a pathogenic haemoflagellate of salmonids on the west coast of North America (Woo 1987, 1991, 1994) and the mechanism of the parasitic disease is not well understood (Woo \& Poynton 1995). Infected rainbow trout Oncorhynchus mykiss are anorexic (Li \& Woo 1991, Thomas \& Woo 1992), and develop anaemia, exophthalmia, splenomegaly, abdominal distension with ascites and general oedema (Woo 1979). Although parasitaemias are very high, infected brook charr do not show clinical cryptobiosis (Ardelli et al. 1994, Forward et al. 1995).

Proteases are known to contribute to protozoan diseases in mammals (Coombs 1982, Gadasi \& Kobiler 1983, Dluzewski et al. 1986, Pupkis et al. 1986), but

•Addressee for correspondence. E-mail: pwoo@uoguelph.ca their roles in fish disease are not well documented. Our earlier study showed that the pathogenic strain of $C$. salmositica has cysteine and metallo-proteases and the parasite losses the metallo-protease as it becomes less virulent during in vitro culture (Zuo \& Woo 1997a this issue). Also, the nonpathogenic C. catostomi of white suckers Catostomus commersoni has only cysteine protease and its proteolytic activity is much lower than that in the pathogenic C. salmositica (Zuo \& Woo 1997a). We earlier suggested that the metallo-protease in the pathogenic C. salmositica is related to its pathogenicity in fish (Zuo \& Woo 1997a, b)

We showed that plasma $\alpha 2$-macroglobulin $(\alpha 2-\mathrm{M})$ in rainbow trout and brook charr inhibited Cryptobia salmositica proteases under in vitro conditions and that $\alpha 2-\mathrm{M}$ was neutralized after the parasites were cultured in the fish blood (Zuo \& Woo 1997a).

The main objectives of the present study were to determine the in vivo neutralization of the natural 
antiprotease $\alpha 2-\mathrm{M}$ by $C$. salmositica proteases, and the relationship between antiprotease activity and anaemia in infected fish.

\section{MATERIALS AND METHODS}

Fishes. Ten laboratory-raised Cryptobia-susceptible brook charr Salvelinus fontinalis ( 3 yr old; 1509 to $2180 \mathrm{~g}$ ) (Forward et al. 1995) and 10 rainbow trout Oncorhynchus mykiss (3 yr old; 1459 to 1902 g) from a disease-free hatchery (Wildcat Trout Farm, Thamesford, Canada) were used in this study. All fishes were kept in fibre glass tanks supplied with running well water and continuous aeration and fed to satiety once daily with a $52 \%$ protein diet (3 GR trout pellets, Martin Feed Mills, Elmira, Canada).

Bleeding of fish. Fish were anaesthetized in a solution of Tricaine methane sulfonate (MS-222, Finquel Brand, Argent Chemical Laboratories, WA, USA) before bleeding. A disposable sterile needle $\left(25 \mathrm{G}^{5 / 8}\right)$ and a $3 \mathrm{ml}$ disposable plastic syringe with heparinized saline $[0.1 \mathrm{~g}$ heparin added to $10 \mathrm{ml}$ of cold-blooded vertebrate Ringer's solution (CBVR)] were used to draw blood from the caudal vein of infected fish (Forward et al. 1995). Blood samples were kept on ice until use.

Infection of fish with pathogenic Cryptobia salmositica. The parasite was obtained from an infected rainbow trout. Each of the 5 brook charr and 5 rainbow trout was inoculated intraperitoneally (i.p.) with 250000 parasites (in $0.2 \mathrm{ml}$ of CBVR) (experimental group) and 5 charr and 5 trout were inoculated i.p. with $0.2 \mathrm{ml}$ of CBVR (control group). Blood (1 ml) was taken weekly from fish and the number of parasites and packed cell volume were determined. The remaining blood was centrifuged at $1350 \times g$ for $10 \mathrm{~min}$ at $4^{\circ} \mathrm{C}$, and the supernatant (fish plasma) was used fresh or stored at $-100^{\circ} \mathrm{C}$ for $<6$ mo. Our preliminary study indicated that storage at $-100^{\circ} \mathrm{C}$ did not affect the effectiveness of fish antiproteases.

Parasite count and determination of packed blood cell volume. Parasitaemias were determined using a haemocytometer (Archer 1965). Low parasitaemia were detected using the haematocrit centrifuge technique (Woo \& Wehnert 1983). Packed blood cell volume was determined using a haematocrit centrifuge $(13600 \times g$ for $4 \mathrm{~min}$ ) (Woo \& Li 1990).

Detection of $\alpha 2$-macroglobulin $(\alpha 2-M)$ in fish plasma. The method was that of Ellis (1990) with some modifications. Briefly, $100 \mu \mathrm{l}$ trypsin (bovine pancreas type III, Sigma) $\left(100 \mu \mathrm{g} \mathrm{ml}^{-1}\right.$ of $0.1 \mathrm{M}$ Tris- $\mathrm{HCl}, \mathrm{pH}$ 8.2) was incubated with $50 \mu \mathrm{l}$ of fish plasma for $10 \mathrm{~min}$ at $22^{\circ} \mathrm{C}$. Tris buffer $(0.1 \mathrm{M}, \mathrm{pH} 8.2)$ was added to bring the volume to $2.5 \mathrm{ml}$, and $2 \mathrm{ml}$ of $\mathrm{Na}$-benzoyl-DL-argininep-nitroanilide $\mathrm{HCl}$ (BAPNA, Sigma) was added and then incubated at $22^{\circ} \mathrm{C}$ for $25 \mathrm{~min}$. The reaction was terminated by the addition of $0.6 \mathrm{ml} 30 \%$ acetic acid. Fine precipitates were removed by filtration using a $0.22 \mu \mathrm{m}$ Millipore filter and the optical density of the filtrate was measured at $410 \mathrm{~nm}$ using a spectrophotometer against an appropriate blank. The blank was prepared individually by adding acetic acid to the enzyme/plasma mixture prior to addition of the substrate.

Inhibitory capacity of $\alpha 2-\mathrm{M}$ was expressed as inhibition on trypsin activity, i.e. a percentage of the difference between the control activity (A1) (without the antiprotease) and the activity remaining (A2) (after incubation with the antiprotease) in the control activity (A1). The formula is as follow:

$$
\text { Inhibitory capacity }(\%)=\frac{\mathrm{A} 1-\mathrm{A} 2}{\mathrm{~A} 1} \times 100 \%
$$

Detection of extracellular proteases of Cryptobia salmositica in the blood of infected fish. The proteolytic activity in the fish plasma was determined using azocoll as the substrate (Arnesen et al. 1995) with a slight modification. Briefly, $50 \mu \mathrm{l}$ of fish plasma was incubated with $300 \mu \mathrm{HEPES} / \mathrm{CaCl}_{2}$ buffer $(0.1 \mathrm{M}$ HEPES, pH 7.5, supplemented with $4 \mathrm{mM} \mathrm{CaCl}_{2}$ ) and $300 \mu \mathrm{l}$ azocoll $\left(10 \mathrm{mg} \mathrm{ml}^{-1}\right.$ water, Sigma) at $37^{\circ} \mathrm{C}$ for $12 \mathrm{~h}$. The reaction was stopped by adding $50 \mu \mathrm{l}$ of $50 \%$ trichloroacetic acid (TCA). The absorbance was measured using a spectrophotometer at $520 \mathrm{~nm}$ against the blank. The blank was prepared individually by adding the TCA to the protease sample prior to addition of the substrate. To confirm that the protease is a metalloprotease, proteolytic activity was also assayed after the sample was pre-incubated with 1,10-phenanthroline (Sigma, at final concentration of $1 \mathrm{mM}$ ), a metalloprotease inhibitor (North et al. 1983).

Polyacrylamide-substrate gel. Electrophoretic separation of the proteases of Cryptobia salmositica was performed on non-reducing SDS-polyacrylamide gels (7.5\%) copolymerized with $0.1 \%$ gelatin (Sigma) using a Mini-protean II dual slab cell (BioRad, Canada) (Britton et al. 1992). A $20 \mu \mathrm{l}$ of cell lysate (containing $20 \mu \mathrm{g}$ protein) or $30 \mu \mathrm{l}$ of fish plasma was mixed with $10 \mu \mathrm{l}$ of SDS-sample buffer $(0.5 \mathrm{M}$ Tris- $\mathrm{HCl}, \mathrm{pH} 6.8$, $10 \%$ SDS, $20 \%$ glycerol and $0.02 \%$ bromophenol blue) and applied to the gel, without boiling. After electrophoresis the gels were immersed in $1 \mathrm{l}$ of $2.5 \%(\mathrm{v} / \mathrm{v})$ Triton X-100 for $1 \mathrm{~h}$ to remove SDS. The protease bands were developed by immersing the gels in the $\mathrm{HEPES} / \mathrm{CaCl}_{2}$ buffer (see above) for $12 \mathrm{~h}$ at $37^{\circ} \mathrm{C}$. Zones of proteolysis were clear bands against a blue background after Coomassie Blue R-250 staining (0.1\%) and molecular weights of individual protease were determined based on their mobility relative to those of molecular weight standards (Britton et al. 1992). 
Statistical analysis. The Student $t$-test (Wardlaw 1985) was used to determine the significant difference in parasitaemia, packed cell volume, inhibitory capacity of antiprotease and proteolytic activity. Results were considered significant if $\mathrm{p}<0.05$.

\section{RESULTS}

\section{Parasitaemias in infected fishes}

All 5 rainbow trout were infected post-inoculation of Cryptobia salmositica (p.i.) and the mean parasitaemia was high. The parasitaemia peaked at $5 \mathrm{wk}$ p.i. and it fluctuated during the infection (Fig. 1).

All 5 brook charr were also infected and the highest number was at 4 wk p.i. (Fig. 1). Parasitaemias in infected trout and charr at 1 to $4 \mathrm{wk}$ p.i. were not significantly different ( $p>0.05$ ). The parasitaemia in infected charr declined at 5 wk p.i. and it remained low with no fluctuation (Fig. 1).

\section{Packed blood cell volumes}

Significant differences $(\mathrm{p}<0.05)$ in packed blood cell volume were detected between control and infected rainbow trout 4 to $7 \mathrm{wk}$ p.i., i.e. infected trout had significantly lower packed blood cell volume $(p<0.05)$ than control fish (Fig. 2A). However, no significant difference ( $p>0.05$ ) was found between control and infected brook charr (Fig. 2B), indicating that infected charr were not anaemic.

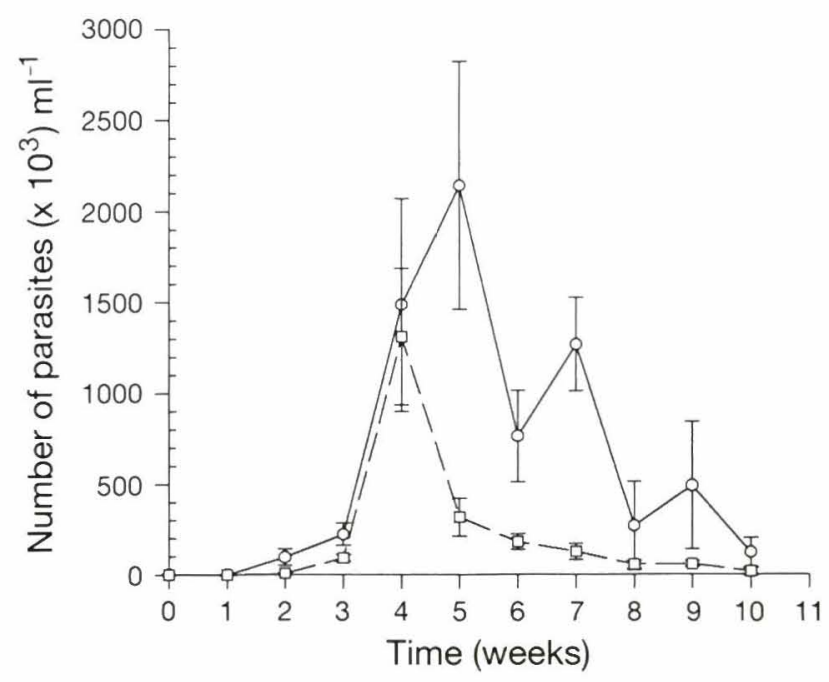

Fig. 1. Parasitaemia of Cryptobia salmositica in infected fishes. Each point is the mean \pm standard deviation $(n=5)$. (0) Rainbow trout (Oncorhynchus mykiss); (a) brook charr Salvelinus fontinalis

\section{Neutralization of plasma $\alpha 2-\mathrm{M}$ by Cryptobia salmositica proteases in infected fishes}

The inhibitory capacity of $\alpha 2-\mathrm{M}$ in rainbow trout were constant for $2 \mathrm{wk}$ prior to infection and for $2 \mathrm{wk}$ p.i. (Fig. 3A); these were not significantly different $(p>0.05)$ from those in uninfected controls. However, from 3 to $8 \mathrm{wk}$ after infection, the inhibitory capacities of $\alpha 2-M$ were significantly lower $(p<0.05$ ) than those in the control group (Fig. 3A). This indicates that significant amounts of the $\alpha 2-\mathrm{M}$ were neutralized by $C$. salmositica extracellular proteases. The $\alpha 2-\mathrm{M}$ activity was lowest in infected trout at $5 \mathrm{wk}$ p.i. (Fig. 3A). This was when fish had the highest parasitaemia (Fig. 1) and the lowest packed blood cell volume (Fig. 2A).

However, there was no significant decrease in the inhibitory capacity of $\alpha 2-\mathrm{M}$ in infected brook charr compared to uninfected controls except at 4 and $5 \mathrm{wk}$ p.i. (Fig. 3B). At 4 wk p.i. infected charr had the highest parasitaemia and the lowest $\alpha 2-\mathrm{M}$; however, the inhibitory capacity of $\alpha 2-\mathrm{M}$ (Fig. 3B) was still significantly higher $(p<0.05)$ than that in infected trout (Fig. 3A).

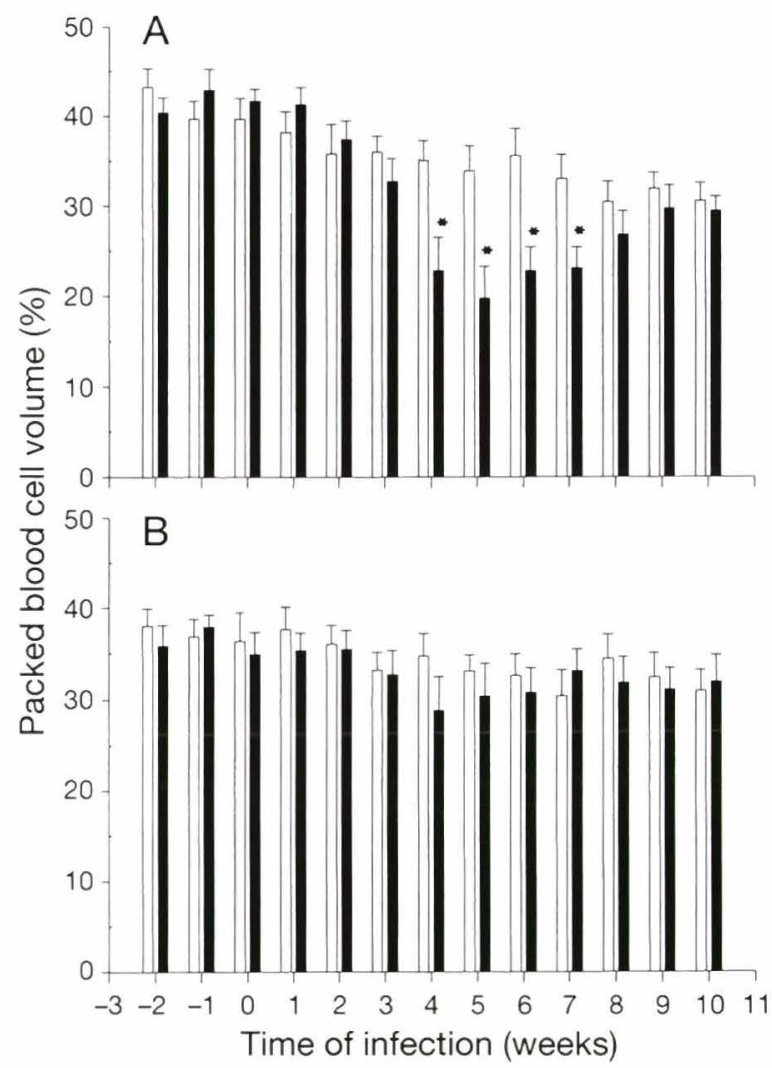

Fig. 2. Packed blood cell volume (\%) in fishes. (A) Rainbow trout Oncorhynchus mykiss; (B) brook charr Salvelinus fontinalis. Each bar represents the mean packed blood cell volume ( \pm standard deviation, $n=5$ ). Open bars: control group (uninfected fish); solid bars: experimental group (infected fish). - Significantly lower $(p<0.05)$ than that in the control group 


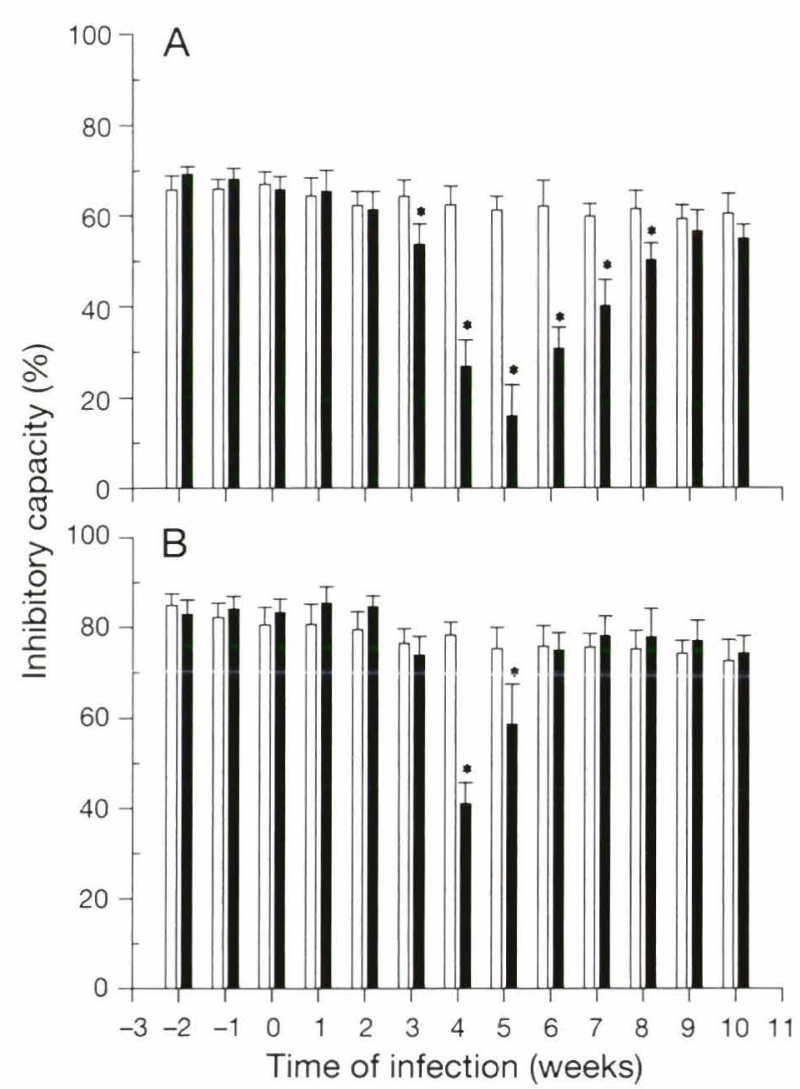

Fig. 3. Inhibitory capacity of $\alpha 2-\mathrm{M}$ in fishes. (A) Rainbow trout; (B) brook charr. Each bar represents the mean inhibitory capacity ( \pm standard deviation, $n=5$ ). Empty bar: control group (uninfected fish); solid bar: experimental group (infected fish). - Significantly lower $(p<0.05)$ than that in the control group

\section{Secreted metallo-protease of Cryptobia salmositica in the blood of infected fishes}

No proteolytic activity was detected in plasma of uninfected rainbow trout nor in plasma of uninfected and infected brook charr. However, proteolytic activities were detected in the plasma of infected rainbow trout at 4,5 , and $6 \mathrm{wk}$ p.i. (Table 1). The activities were significantly inhibited by 1,10-phenanthroline, an inhibitor for metallo-proteases (Table 1). This indicates that the secreted protease is a metallo-protease.

Secreted metallo-protease was also detected in plasma of infected trout at 4,5, and 6 wk p.i. using the gelatin-SDS-PAGE (Fig. 4). This proteolytic activity appeared as a single clear band (about 200 to $205 \mathrm{kDa}$ ) after Coomassie blue staining; protease with similar molecular weight but with much higher activity was also found in C. salmositica lysate (Fig. 4). No protease band was detected in plasma of uninfected trout (lane 4, Fig. 4), nor in plasma of uninfected and infected brook charr.
Table 1. Protease activity secreted by Cryptobia salmositica in the blood of infected rainbow trout Oncorhynchus mykiss and the inhibition by 1,10-phenanthroline. The activity is in absorbance assayed using azocoll as substrate (at $520 \mathrm{~nm}$ ); mean \pm standard deviation from 5 individual fish. Control activity is the activity detected without inhibitor; inhibited acitivity is the activity detected with inhibition of 1,10 phenanthroline (1 $\mathrm{mM})$

\begin{tabular}{|c|c|c|}
\hline Week p.i. & Control activity & Inhibited activity \\
\hline 3 & nd & nd \\
\hline 4 & $0.060 \pm 0.014$ & $\begin{array}{c}0.005 \pm 0.002 \cdot \\
(8.3 \%)^{\mathrm{a}}\end{array}$ \\
\hline 5 & $0.092 \pm 0.015$ & $\begin{array}{c}0.012 \pm 0.0044^{\circ} \\
\quad(13.0 \%)^{\mathrm{a}}\end{array}$ \\
\hline 6 & $0.026 \pm 0.008$ & $\begin{array}{c}0.004 \pm 0.002 \\
\quad(15.4 \%)^{\mathrm{a}}\end{array}$ \\
\hline 7 & nd & nd \\
\hline \multicolumn{3}{|c|}{$\begin{array}{l}- \text { Significantly lower }(p<0.05) \text { than the control activity } \\
\text { activity remaining was given as a percentage in the } \\
\text { control activity; nd: no proteolytic activity was detected } \\
\text { (the absorbance was } \leq 0 \text { ) }\end{array}$} \\
\hline
\end{tabular}

\section{DISCUSSION}

Cryptobia salmositica infects both rainbow trout and brook charr, but it only causes disease (e.g. anaemia) in trout and not in charr although the parasitaemia may be as high or higher in charr (Ardelli et al. 1994, Forward et al. 1995).

The first clinical sign of cryptobiosis in rainbow trout is the anaemia, and this is correlated with increasing parasitaemia (Woo 1979). There are 2 haemolytic components in Cryptobia salmositica which contribute to the anaemia: a 'lytic' component which causes lysis of erythrocytes independent of antibody or complement, and an 'immune complex-forming' component which binds to erythrocytes to form immune complex with specific antibody and activates complement which results in haemolysis (Thomas \& Woo 1988). These haemolytic components are also secreted by live C. salmositica under in vitro conditions (Woo \& Thomas 1992). However, their biochemical nature is not clear, although they were suggested to be proteinaceous in nature (Thomas \& Woo 1989).

We (Zuo \& Woo 1997a) showed that the pathogenic Cryptobia salmositica has 2 types of proteases (cysteine protease and metallo-protease) and that the parasite has lost its metallo-protease after it becomes avirulent. Also, the nonpathogenic C. catostomi of white suckers Catostomus commersoni has only cysteine protease. We (Zuo \& Woo 1997b) also demonstrated that the purified metallo-protease from the pathogenic $C$. salmositica causes in vitro lysis of fish erythrocytes. In the present study, the secreted 


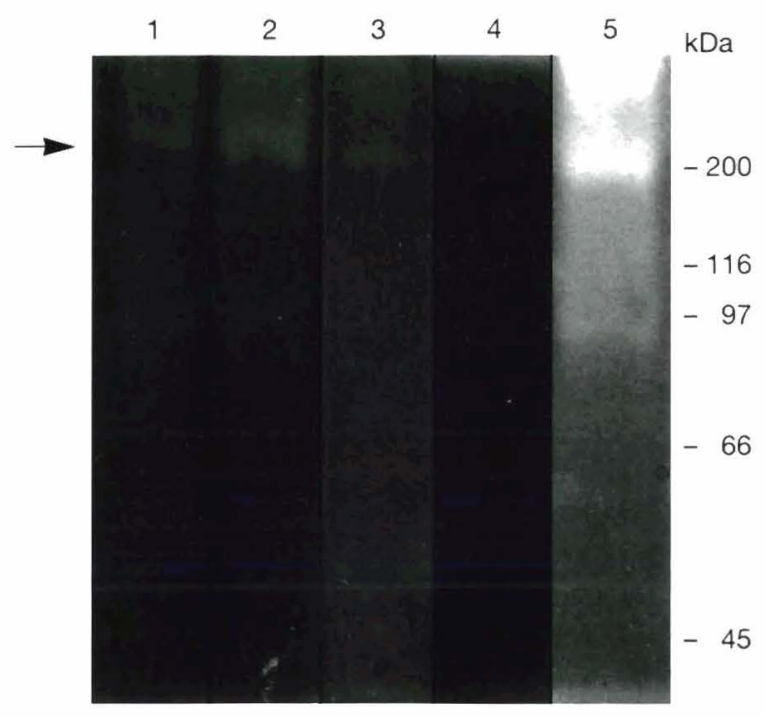

Fig. 4. Protease activity of Cryptobia salmositica detected using the gelatin-SDS-PAGE. Lanes 1, 2, 3: secreted protease (indicated by arrow) from plasma of infected rainbow trout at $4,5,6$ wk p.i., respectively; lane 4: plasma of an uninfected rainbow trout; lane 5: intracellular protease from cell lysate of C. salmositica. Standard molecular mass markers (kDa) as indicated

metallo-protease was detected in the blood of infected rainbow trout (Table 1, Fig. 4) at a time when the level of natural antiprotease $\alpha 2-\mathrm{M}$ was low (Fig. 2). The metallo-protease could be secreted by live parasites or was released from broken parasites lysed by fish complement (Li \& Woo 1995). We suggest that the metalloprotease contributes to the anaemia in cryptobiosis and that it is likely the secreted 'lytic component' detected in earlier studies (Thomas \& Woo 1988, 1989, Woo \& Thomas 1992).

There are good indications that $\alpha 2-\mathrm{M}$ contributes to defence against diseases caused by pathogens which secrete proteolytic enzymes. It is believed that the extracellular protease and elastase produced by Pseudomonas aeruginosa, in burned and compromised patients, are virulence factors and the human $\alpha 2-\mathrm{M}$ greatly reduces the disease by inhibiting the proteolytic activity of the bacterium (Holder \& Haidaris 1979). The protease released by the bovine protozoan Tritrichomonas foetus is neutralized by $\alpha 2-\mathrm{M}$, but not by $\alpha 1-$ PI. This neutralization inhibits the action of the secreted protease (Talbot et al. 1991). The fish pathogen Aeromonas salmonicida secretes protease that depletes $\alpha 2-\mathrm{M}$ in rainbow trout and contributes to pathogenesis (Ellis et al. 1981, Hastings \& Ellis 1985), and the fish $\alpha 2-\mathrm{M}$ plays an important role in defence against furunculosis because it inhibits bacterial protease (Ellis 1987).

In the present study, there was no significant difference in parasitaemias between infected rainbow trout and brook charr at 1 to 4 wk p.i. However, the rainbow trout developed anaemia and the brook charr did not. The $\alpha 2-\mathrm{M}$ was significantly higher in infected charr than in infected trout, and the $\alpha 2-\mathrm{M}$ in the trout markedly decreased with the increasing parasitaemia during the infection. Even after infected trout had recovered from the anaemia (at $8 \mathrm{wk}$ p.i.), the $\alpha 2-\mathrm{M}$ activity was still significantly lower than those in uninfected controls. This indicates that infected trout were slow to produce $\alpha 2-\mathrm{M}$. The level of $\alpha 2-\mathrm{M}$ in infected charr remained high during the infection and there was no anaemia. In another study (Zuo \& Woo $1997 \mathrm{~b})$ we showed that plasma of rainbow trout and brook charr (containing $\alpha 2-\mathrm{M}$ ) prevents in vitro haemolysis caused by the purified metallo-protease from Cryptobia salmositica, and that charr has significantly higher $\alpha 2-\mathrm{M}$ activity than trout in the same amount of plasma. It is likely that a quantitative difference in $\alpha 2-\mathrm{M}$ between charr and trout is one of the reasons that trout suffers from cryptobiosis while charr does not. We suggest that $\alpha 2-\mathrm{M}$, a natural protease inhibitor, is one of defensive factors against cryptobiosis; the high activity of the $\alpha 2-\mathrm{M}$ in the brook charr before and after infection is the reason that the fish does not suffer from cryptobiosis. Even in the susceptible rainbow trout, its plasma $\alpha 2-\mathrm{M}$ has a defensive function in that it delays the onset (e.g. anaemia) and also reduces the severity of the disease.

Acknowledgements. This study was supported by the grants from the Department of Fisheries and Ocean (Canada) and the Natural Sciences and Engineering Research Council (Canada) to P.T.K.W

\section{LITERATURE CITED}

Archer RK (1965) Haematological techniques for use on animals. Blackwell Scientific Publication, Oxford

Ardelli BF, Forward GM, Woo PTK (1994) Brook charr, Salvelinus fontinalis (Mitchill), and cryptobiosis: a potential salmonid reservoir host for Cryptobia salmositica Katz, 1951. J Fish Dis 17:567-577

Arnesen JA, Eggset G, Jørgensen TO (1995) Partial purification and characterization of extracellular metalloproteases from Aeromonas salmonicida ssp. J Fish Dis 18:283-295

Britton C, Knox DP, Canto GJ, Urquhart GM, Kennedy MW (1992) The secreted and somatic proteinases of the bovine lungworm Dictyocaulus viviparus and their inhibition by antibody from infected and vaccinated animals. Parasitology 105:325-333

Coombs GH (1982) Proteinases of Leishmania mexicana and other flagellate protozoa. Parasitology 84:149-155

Dluzewski AR, Rangachari K, Wilson RJM, Gratzer WB (1986) Plasmodium falciparum: protease inhibitors and inhibition of erythrocyte invasion. Expl Parasitol 62:416-422

Ellis AE (1987) Inhibition of the Aeromonas salmonicida extracellular protease by $\alpha 2$-macroglobulin in the serum of rainbow trout. Microb Pathol 3:167-177

Ellis AE (1990) Serum antiproteases in fish. In: Stolen JS, 
Fletcher TC, Anderson DP, Roberson BS, van Muiswinkel WB (eds) Techniques in fish immunology. SOS Publications, Fair Haven, p 95-99

Ellis AE, Hastings TS, Munro ALS (1981) The role of Aeromonas salmonicida extracellular products in the pathology of furunculosis. J Fish Dis 4:41-52

Forward GM, Ferguson MM, Woo PTK (1995) Susceptibility of brook charr, Salvelinus fontinalis to the pathogenic haemoflagellate, Cryptobia salmositica, and the inheritance of innate resistance by progenies of resistant fish. Parasitology 111:337-345

Gadasi H, Kobiler D (1983) Entamoeba histolytica: correlation between virulence and contents of proteolytic enzymes. Expl Parasitol 55:105-110

Hastings TS, Ellis AE (1985) Differences in production of haemolytic and proteolytic activities by various isolates of Aeromonas salmonicida. In: Ellis AE (ed) Fish and shellfish pathology. Academic Press, London, p 98-106

Holder LA, Haidaris CG (1979) Experimental studies of the pathogenesis of infections due to Pseudomonas aeruginosa: extracellular protease and elastase as in vivo virulence factors. Can J Microbiol 25:593-599

Li S, Woo PTK (1991) Anorexia reduces the severity of cryptobiosis in Oncorhynchus mykiss. J Parasitol 77:467-471

Li S, Woo PTK (1995) Efficacy of a live Cryptobia salmositica vaccine, and the mechanism of protection in vaccinated rainbow trout Oncorhynchus mykiss, against cryptobiosis. Vet Immunol Immunopathol 48:343-353

North MJ, Coombs GH, Barry JD (1983) A comparative study of the proteolytic enzymes of Trypanosoma brucei, $T$. equiperdum, $T$. evansi, $T$. vivax, Leishmania tarentolae and Crithidia fasciculata. Mol Biochem Parasitol 9. 161-180

Pupkis MF, Tetley L, Coombs GH (1986) Leishmania mexicana: amastigote hydrolase in unusual lysosomes. Expl Parasitol 62:29-39

Talbot JA, Neilsen K, Corbeil LB (1991) Cleavage of proteins of reproductive secretions by extracellular proteases of Tritrichomonas foetus. Can J Microbiol 37:384-390

Thomas PT, Woo PTK (1988) Cryptobia salmositica: an in vitro study on the mechanism of anaemia in infected rainbow trout, Salmo gairdneri Richardson. J Fish Dis 11: $425-431$

Thomas PT, Woo PTK (1989) An in vitro study on the haemo-

Responsible Subject Editor: W. Körting, Hannover, Germany lytic components from Cryptobia salmositica (Sarcomastigophora: Kinetoplastida). J Fish Dis 12:389-393

Thomas PT, Woo PTK (1992) Anorexia in Oncorhynchus mykiss infected with Cryptobia salmositica (Sarcomastigophora: Kinetoplastida): its onset and contribution to the immunodepression. J Fish Dis 15:443-447

Wardlaw AC (1985) Practical statistics for experimental biologists. Wiley-Interscience, Chichester

Woo PTK (1979) Trypanoplasma salmositica: experimental infections in rainbow trout, Salmo gairdneri. Expl Parasitol 47:36-48

Woo PTK (1987) Cryptobia and cryptobiosis in fishes. In: Baker JR, Muller R (eds) Advances in parasitology, Vol 26. Academic Press, London, p 199-237

Woo PTK (1991) Mammalian trypanosomiasis and piscine cryptobiosis in Canada and the United States. Bull Soc Vector Ecol 16:25-42

Woo PTK (1994) Flagellate parasites of fish. In: Kreier JP (ed) Parasitic protozoa, Vol 8. Academic Press, San Diego, p $1-80$

Woo PTK, Li S (1990) In vitro attenuation of Cryptobia salmositica and its use as a live vaccine against cryptobiosis in Oncorhynchus mykiss. J Parasitol 76:752-755

Woo PTK, Poynton SL (1995) Diplomonadida, kinetoplastida and amoebida (Phylum Sarcomastigophora). In: Woo PTK (ed) Fish diseases and disorders, I: Protozoan and metazoan infections. CAB International, Wallingford, p 27-96

Woo PTK, Thomas PT (1992) Comparative in vitro studies on virulent and avirulent strains of Cryptobia salmositica (Sarcomastigophora: Kinetoplastida). J Fish Dis 15:261-266

Woo PTK, Wehnert SD (1983) Direct transmission of a haemoflagellate, Cryptobia salmositica (Kinetoplastida: Bodonina) between rainbow trout under laboratory conditions. J Protozool 30:334-337

Zuo X, Woo PTK (1997a) Proteases in pathogenic and nonpathogenic haemoflagellate Cryptobia spp. (Sarcomastigophora: Kinetoplastida), of fishes. Dis Aquat Org 29: $57-65$

Zuo X, Woo PTK (1997b) Natural antiproteases in rainbow trout, Oncorhynchus mykiss and brook charr, Salvelinus fontinalis and the in vitro neutralization of fish $\alpha 2$ macroglobulin by the metallo-protease from the pathogenic haemoflagellate, Cryptobia salmositica. Parasitology (in press)

Manuscript first received: October 18, 1996 Revised version accepted: January 4, 1997 


\title{
A systemic parvo-like virus in the freshwater crayfish Cherax destructor
}

\author{
Brett Edgerton ${ }^{1, *}$, Richard Webb ${ }^{2}$, Max Wingfield ${ }^{3}$ \\ ${ }^{1}$ Department of Biomedical and Tropical Veterinary Sciences, James Cook University of North Queensland, Townsville, \\ Queensland 4811, Australia
}

${ }^{2}$ Department of Microbiology and Centre for Microscopy and Microanalysis, University of Queensland, Queensland 4072, Australia

${ }^{3}$ Fisheries Department, Department of Primary Industries South Australia, 25 Grenfell St., Adelaide, South Australia 5000, Australia

\begin{abstract}
Systemic Cowdry Type A inclusions (CAs) were observed in a moribund Cherax destructor collected at an aquaculture farm in South Australia. Inclusions were most common in the gills and were associated with multifocal necrosis of the main gill axis and lamellae. The hepatopancreas was necrotic; however, only one CA was observed in the interstitial tissues. CAs were associated with necrosis in the abdominal and gut musculature. CAs were also observed in the spongy connective tissues and the epicardium. Empty capsids $(17.5 \pm 0.5 \mathrm{~nm})$ and microfilaments were most commonly observed within these inclusions by transmission electron microscopy. Complete icosahedral viral particles $(20.8 \pm 1.2 \mathrm{~nm})$ were difficult to distinguish within the viroplasm, but were visualised better in aggregates between the viroplasm and the inner nuclear membrane. The nucleolus was closely associated with the developing viroplasm, and was hypertrophied and segregated into its fibrillar and granular components. The virus was named Cherax destructor systemic parvo-like virus (CdSPV) on the basis of its histopathology, cytopathology and morphology. CdSPV is the first systemic virus described in a freshwater crayfish.
\end{abstract}

KEY WORDS: Crayfish · Cherax destructor - Systemic parvo-like virus · Histopathology · Cytopathology

\section{INTRODUCTION}

Viruses have been described in a number of freshwater crayfish species since the discovery of the initial freshwater crayfish virus, Cherax quadricarinatus bacilliform virus, by Anderson \& Prior (1992). Most are intranuclear bacilliform viruses which infect the gut (Hedrick et al. 1995, Edgerton 1996, Edgerton et al. 1996). The one exception is Cherax Giardiavirus-like virus (CGV), a dsRNA virus which infects hepatopancreatocytes in C. quadricarinatus (Edgerton et al. 1994).

Parvoviruses assigned to the Densovirinae subfamily infect arthropods (Murphy et al. 1995), including a number of commercially important crustaceans. Hepa-

\footnotetext{
- Present address: Queensland Department of Primary Industries, Oonoonba Veterinary Laboratory, PO Box 1085, Townsville, Queensland 4810, Australia.

E-mail: edgertb@dpi.qld.gov.au
}

topancreatic parvovirus (HPV) infects the hepatopancreatocytes of a range of penaeid species (Lightner \& Redman 1985, Lightner 1996), and a morphologically indistinguishable virus also infects the giant freshwater prawn Macrobrachium rosenbergii (Anderson et al. 1990). Mari \& Bonami (1988) described a systemic parvovirus, which they named PC84, in the crab Carcinus mediterraneus. Infectious hypodermal and haematopoietic necrosis virus (IHHNV) is possibly the best known crustacean parvovirus, due to its well documented pathogenicity and its wide host and geographical range (Brock \& Lightner 1990). IHHNV has also been described in experimental hybrid penaeids in Australia (Owens et al. 1992). Lymphoidal parvolike virus was described in 3 penaeid species in Australia (Owens et al. 1991). The viruses PC84, HPV and IHHNV have been characterised physicochemically to confirm their relatedness to the Parvoviridae (Mari \& Bonami 1988, Bonami et al. 1990, Bonami et al. 1995). The Australian viruses do not react with DNA probes 
for these viruses (Lightner 1996) and are uncharacterised.

A parvo-like virus was associated with Cowdry Type A inclusions in a moribund Cherax destructor during an ongoing surveillance of farmed crayfish for disease. This paper describes the histopathology, cytopathology and morphology of the agent.

\section{MATERIALS AND METHODS}

One moribund Cherax destructor was collected at an aquaculture farm in South Australia. The crayfish was sacrificed immediately by severing the cephalothorax from the abdomen. The cephalothorax was then split longitudinally and placed in Davidson's solution with the abdomen. Tissues were processed and histological sections were prepared conventionally (Culling et al. 1985) on arrival at the laboratory. Sections were stained with H\&E, Feulgen and phloxine and tartrazine stains. Histological sections were viewed using a Leitz Orthoplan microscope.

Davidson's fixed gill tissues were also used for electron microscopy. Gill tissue was re-fixed in 3\% glutaraldehyde in $0.1 \mathrm{M}$ cacodylate buffer overnight at $4^{\circ} \mathrm{C}$, washed 3 times in $0.1 \mathrm{M}$ cacodylate buffer, post-fixed for $1 \mathrm{~h}$ at room temperature in $1 \%$ osmium tetroxide in $0.1 \mathrm{M}$ cacodylate buffer, washed 3 times in $0.1 \mathrm{M}$ cacodylate buffer, dehydrated through an acetone series, and embedded in Epon. Ultrathin sections were cut using a Reichert-Jung Ultracut E ultramicrotome, stained with uranyl acetate and lead citrate, and were viewed using a Jeol 1010 transmission electron microscope.

\section{RESULTS}

\section{Gross symptoms}

The crayfish was extremely morbid and was easily collected by hand on the pond bank. The ventral surface of the abdomen exhibited patches of opaque musculature.

\section{Light microscopy}

Intranuclear, Cowdry Type A inclusions (CAs) were observed systemically in the crayfish and were most common in the gills. Affected nuclei were hypertrophied, had a thin rim of marginated chromatin, and contained a single eosinophilic CA in the centre. The CAs were neutral to very lightly phloxophilic and were Feulgen-negative. The nucleolus, when discernable, was basophilic and was closely associated with the inclusion. Smaller, presumably earlier, inclusions always developed centrally and were lightly eosinophilic.

The gills contained extensive necrotic foci characterised by masses of pyknotic and karyorrhectic nuclei, and major haemocytic infiltration, melanisation and nodulation. Pyknotic nuclei and haemocytic nodules were diffuse throughout non-necrotic tissue. CAs were often observed in gill epithelial cells, and in unidentifiable cells, close to necrotic areas and in areas becoming necrotic (Fig. 1). Gill epithelial cells with hypertrophic nuclei, rarefied chromatin and enlarged nucleoli, but without CAs, were common throughout the gills.

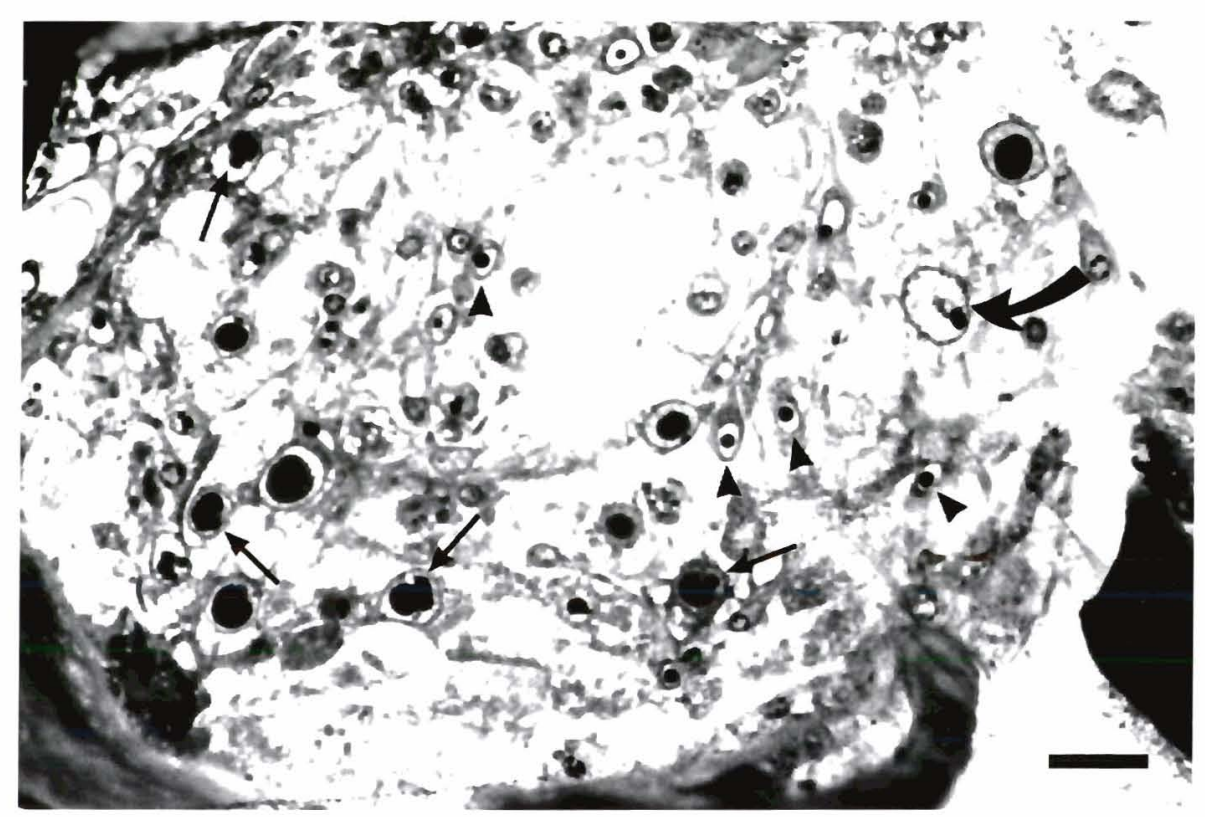

Fig. 1. Light microscopy of Cherax destructor systemic parvo-like virus in Cherax destructor. Many Cowdry Type A intranuclear inclusions in the gill. Note that the inclusions are rounded and are closely associated with the nucleolus (arrows). Note also the many pyknotic nuclei in the area (arrowheads). This area is near to a completely necrotic and melanised area. A hypertrophic nucleus with rarefied chromatin and hypertrophic nucleolus is also present (curved arrow). Toluidine blue. Scale bar $=27 \mu \mathrm{m}$ 
The hepatopancreas and midgut were extensively necrotic. Hepatopancreatocytes were almost exclusively B-cells. Haemocytic infiltrates and small melanitic foci were common in the interstitial tissues of the hepatopancreas and in the midgut submucosa. Haemolymph vessels were only present peripherally in the hepatopancreas, and the endothelial cells and infiltrating haemocytes were usually voluminous or pyknotic. The nucleus of an unidentified cell associated with a haemolymph vessel in the hepatopancreas contained a $\mathrm{CA}$, as did a hindgut myoepithelial cell. Cellular debris and bacteria were distributed throughout the entire gut.

CAs, pyknotic and karyorrhectic nuclei, and haemocytic infiltrates and nodules were also observed in the epicardium, abdominal muscle and spongy connective tissues. Hypertrophic nuclei with rarefied chromatin and prominent nucleoli, but without inclusions, were also common in these tissues.

\section{Electron microscopy}

Gill cells containing CAs were hypertrophied, and had marginated and rarefied chromatin (Fig. 2). A rounded, granular viroplasm was located centrally, closely associated with the hypertrophied nucleolus. The viroplasm contained mostly filamentous structures and rounded $17.5 \pm 0.5 \mathrm{~nm}(\mathrm{n}=7)$ particles with electron-lucent centres, presumed to be empty capsids (Fig. 3). Electron-dense, $20.8 \pm 1.2 \mathrm{~nm}(\mathrm{n}=6)$ particles were difficult to distinguish within the inclusion, but were visualised better in aggregates between the viroplasm and the inner nuclear membrane. Some particles were clearly hexagonal or pentagonal, indicating an icosahedral symmetry. In some nuclei, the area between the inclusion and the nuclear membrane was full of empty capsids. Nucleolar components of infected cells had segregated with the filamentous component vacuolated and surrounded by the granular component. The granules of the granular component were more sharply defined and packed densely together, and fully formed virions were adjacent to the body.

In some nuclei, the nucleolus was hypertrophic, had segregated, and the viroplasm was only just forming (Fig. 4). The developing viroplasm was round and consisted of groups of long microfilaments associated with mostly empty capsids.

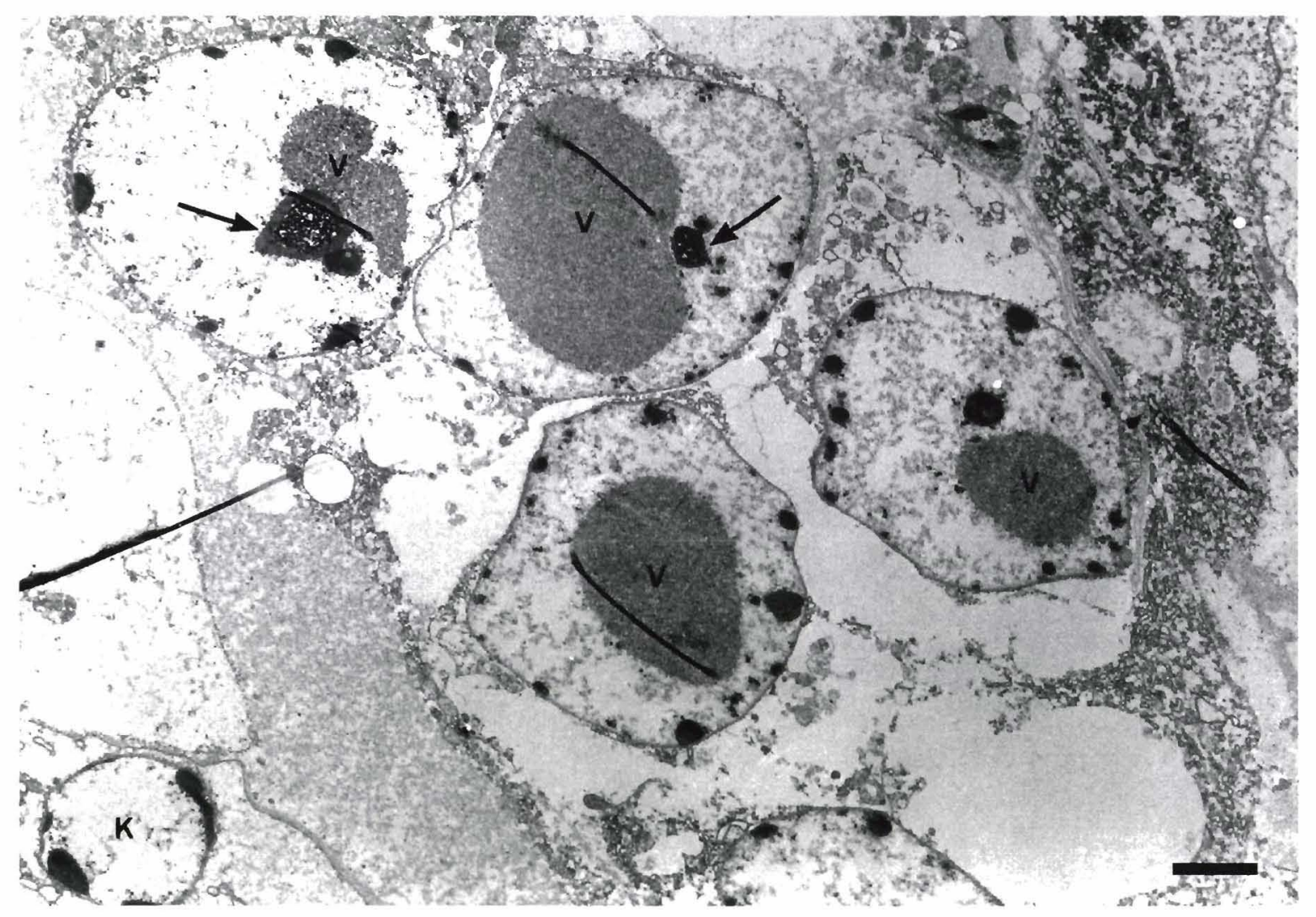

Fig. 2. Electron microscopy of CdSPV in Cherax destructor gill. Low magnification of 4 infected nuclei. Note that chromatin is marginated and rarefied, and the rounded viroplasm (V) is closely associated with the segregated nucleolus (arrows). A karyorrhectic nucleus is adjacent $(\mathrm{K})$. Uranyl acetate and lead citrate. Scale bar $=2.4 \mu \mathrm{m}$ 

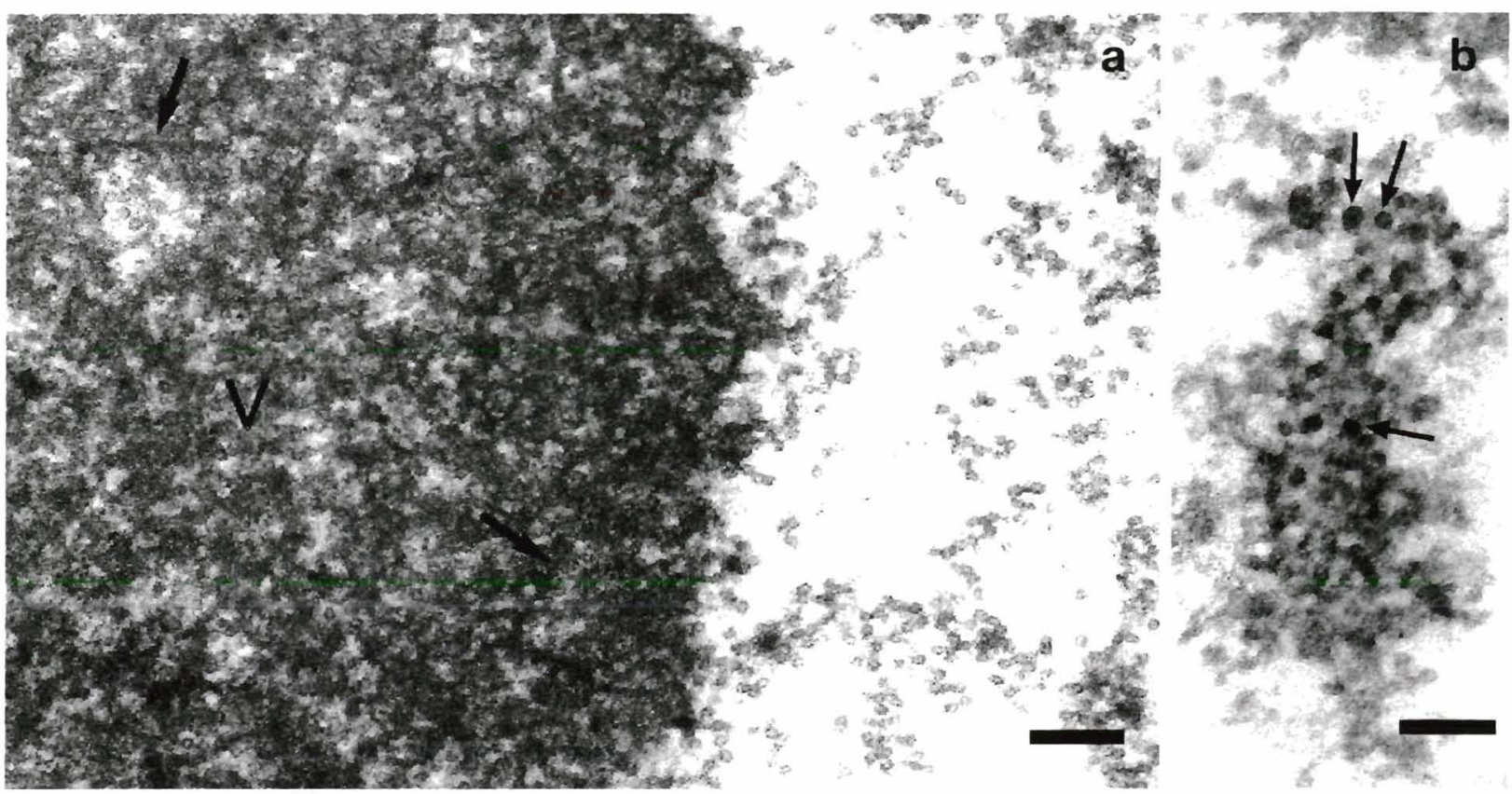

Fig. 3. Electron microscopy of CdSPV in Cherax destructor gill. (a) Higher magnification of CdSPV viroplasm (V) and surrounding area. Note that empty capsids and microfilaments (arrows) are most common within the viroplasm. Empty capsids are abundant in the area surrounding the viroplasm. Uranyl acetate and lead citrate. Scale bar $=130 \mathrm{~nm}$. (b) Cluster of complete CdSPV virions. Note that many virions are angular (arrows). Uranyl acetate and lead citrate. Scale bar $=100 \mathrm{~nm}$

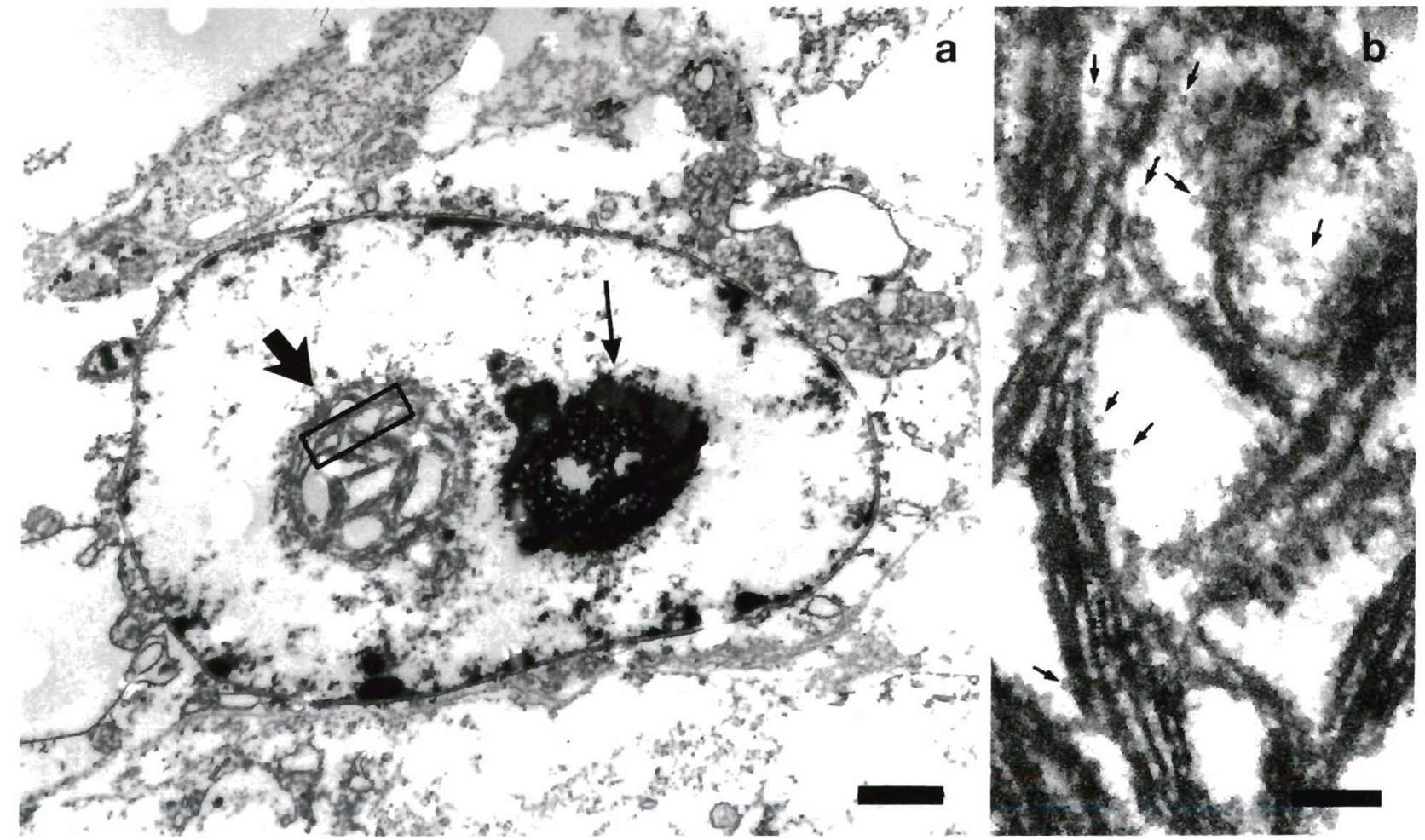

Fig. 4. Electron microscopy of CdSPV in Cherax destructor gill. (a) A nucleus in a presumptive early stage of infection. Note that the nucleolus is hypertrophied and segregated (thin arrow); the fibrous component is vacuolated and is completely surrounded by the granular component. The developing viroplasm (thick arrow) is close to the nucleolus and is round. Uranyl acetate and lead citrate. Scale bar $=1.2 \mu \mathrm{m}$. (b) Higher magnification of the forming viroplasm within the area indicated on (a). Note that empty capsids (arrows) are associated with long microfilaments. Uranyl acetate and lead citrate. Scale bar $=150 \mathrm{~nm}$ 


\section{DISCUSSION}

This is the first systemic virus found in a freshwater crayfish. This agent is clearly different from bacilliform viruses which infect the gut of freshwater crayfish (Anderson \& Prior 1992, Hedrick et al. 1995, Edgerton 1996, Edgerton et al. 1996). It also differs significantly in its tropism, histopathology and cytopathology from CGV which infects hepatopancreatocytes of Cherax quadricarinatus (Edgerton et al. 1994). This virus is similar in size and produces cytopathology reminiscent of parvoviruses; it is between 18 and $25 \mathrm{~nm}$ in diameter, and it replicates in the nucleus in close association with the nucleolus, which is segregated into its fibrillar and granular components. The agent is therefore named Cherax destructor systemic parvo-like virus (CdSPV).

CdSPV was associated with major necroses of vital organs. The CAs were found in close proximity to the large necrotic areas in the gills, and in smaller foci beginning to necrotise. A CA was observed interstitially in the massively necrotic hepatopancreas. CAs were associated with necrotic muscle. Whilst these changes no doubt resulted in the extreme morbidity of this animal, it is impossible to fully understand the involvement of CdSPV with these changes. The pathogenicity of CdSPV is therefore unknown.

The ultrastructural pathology of CdSPV is reminiscent of HPV. Similarly to CdSPV, HPV produces a single rounded virogenic stroma which is closely associated with the nucleolus (Lightner \& Redman 1985). Microfibrils or microtubules are also apparent throughout the viroplasm. Intranuclear bodies, which are characteristically embedded in the viroplasm of HPV (Lightner \& Redman 1985) and other parvoviruses (Garzon \& Kurstak 1976), were not observed in CdSPV. However, the absence of such structures in these preparations may be due to sub-optimal fixation. As the names suggest, HPV has a different tropism to CdSPV. In this respect, CdSPV is similar to PC84 and IHHNV. PC84 also produces microtubules; however, virions were not associated with these, and the authors considered that these structures may characterise abortive morphogenesis (Mari \& Bonami 1988). Neither PC84 nor IHHNV produce a rounded virogenic stroma, and nucleoli dissolve following infection by both viruses (Lightner et al. 1983, Mari \& Bonami 1988). Nucleolar hypertrophy and segregation is characteristic of densovirus (Garzon \& Kurstak 1976) as well as other virus infections; however, this is the first description of such a phenomenon in crustacean parvoviruses. The vacuolation of the fibrous component is reminiscent of canine parvovirus (Paradiso et al. 1982).

CdSPV is the second virus found in Cherax destructor. Virtually nothing is known of the prevalence or impact of these viruses on the $C$. destructor aquaculture industry. C. destructor is the most economically important freshwater crayfish species in Australia, accounting for over $80 \%$ of annual production (various industry sources). Research into the basic biology of these viruses is required to assess the potential threat of these viruses to this developing industry.

Acknowledgements. Laurie Reilly, Department of Biomedical and Tropical Veterinary Sciences, James Cook University, is thanked for histological preparations. The continued support of both Dr Leigh Owens, Department of Biomedical and Tropical Veterinary Sciences, James Cook University, and Prof. John McKenzie, Department of Microbiology, University of Queensland, is appreciated. This research was funded by an Australian Research Council Large Grant (A19332302).

\section{LITERATURE CITED}

Anderson IG, Law AT, Shariff M, Nash G (1990) A parvo-like virus in the giant freshwater prawn, Macrobrachium rosenbergii. J Invertebr Pathol 55:447-449

Anderson IG, Prior HC (1992) Baculovirus infections in the mud crab, Scylla serrata, and a freshwater crayfish, Cherax quadricarinatus, from Australia. J Invertebr Pathol 60:265-273

Bonami JR, Mari J, Poulos BT, Lightner DV (1995) Characterization of hepatopancreatic parvo-like virus, a second unusual parvovirus pathogenic for penaeid shrimps. J Gen Virol 76:813-817

Bonami JR, Trumper B, Mari J, Brehelin M, Lightner DV (1990) Purification and characterization of the infectious hypodermal and haematopoietic necrosis virus of penaeid shrimps. J Gen Virol 71:2657-2664

Brock JA, Lightner DV (1990) Diseases of Crustacea, 3.1: Diseases caused by microorganisms. In: Kinne O (ed) Diseases of marine animals. Biologische Anstalt Helgoland, Hamburg, p 245-349

Culling CFA, Allison RT, Barr WT (1985) Cellular pathology techniques, 4 th edn. Butterworths, London

Edgerton B (1996) A new bacilliform virus in Australian Cherax destructor (Decapoda: Parastacidae) with notes on Cherax quadricarinatus bacilliform virus $(=$ Cherax baculovirus). Dis Aquat Org 27:43-52

Edgerton B, Owens L, Glasson B, De Beer S (1994) Description of a small dsRNA virus from freshwater crayfish, Cherax quadricarinatus. Dis Aquat Org 18:63-69

Edgerton B, Paasonen P, Henttonen P, Owens L (1996) Description of a non-occluded baculovirus from the freshwater crayfish, Astacus astacus. J Invertebr Pathol 68: $187-190$

Garzon S, Kurstak E (1976) Ultrastructural studies on the morphogenesis of the densonucleosis virus (parvovirus). Virology 50:517-431

Hedrick RP, McDowell TS, Friedman CS (1995) Baculoviruses found in two species of crayfish from California. Aquaculture '95, Abstracts: 135

Lightner DV (1996) A handbook of pathology and diagnostic procedures for disease of Penaeid shrimp. World Aquaculture Society, Baton Rouge, Louisiana

Lightner DV, Redman RM (1985) A parvo-like virus disease of Penaeid shrimp. J Invertebr Pathol 45:47-53 
Lightner DV, Redman RM, Bell TA (1983) Infectious hypodermal and hematopoietic necrosis, a newly recognized virus disease of penaeid shrimp. J Invertebr Pathol 42:62-70

Mari J, Bonami JR (1988) PC 84, a parvo-like virus from the crab Carcinus mediterraneus: pathological aspects, ultrastructure of the agent, and first biochemical characterization. J Invertebr Pathol 51:145-156

Murphy FA, Fauquet CM, Mayo MA, Jarvis AW, Ghabrial SA, Summers MD, Martelli GP, Bishop DHL (1995) The classification and nomenclature of viruses: sixth report of the International Committee on Taxonomy of Viruses.

Responsible Subject Editor: J. E. Stewart, Dartmouth, Nova Scotia, Canada
Archives of Virology, Springer Verlag, Wien

Owens L, Anderson IG, Kenway M, Trott L, Benzie JAH (1992) Infectious hypodermal and haematopoietic necrosis virus (IHHNV) in a hybrid penaeid prawn from tropical Australia. Dis Aquat Org 14:219-228

Owens L, De Beer S, Smith J (1991) Lymphoidal parvoviruslike particles in Australian penaeid prawns. Dis Aquat Org 11:129-134

Paradiso PR, Rhode SL (III), Singer II (1982) Canine parvovirus: a biochemical and ultrastructural characterization. J Gen Virol 62:113-125

Manuscript first received: September 5, 1996 Revised version accepted: January 8, 1997 